\title{
How Can Open Standards Be Effectively Implemented in Open Source?
}

\section{Challenges and the ORIOS Project}

\author{
Björn Lundell ${ }^{1}$, Admir Abdurahmanovic ${ }^{2}$, Stefan Andersson ${ }^{4}$, \\ Erik Bergström ${ }^{1}$, Jonas Feist ${ }^{4}$, Jonas Gamalielsson ${ }^{1}$, Tomas Gustavsson ${ }^{2}$, \\ Roger Kahlbom ${ }^{3}$, and Konstantin Papaxanthis ${ }^{2}$ \\ ${ }^{1}$ University of Skövde, Skövde, Sweden \\ \{bjorn. lundell, erik.bergstrom, jonas.gamalielsson\}@his.se \\ ${ }^{2}$ PrimeKey Solutions AB, Solna, Sweden \\ \{admir, tomas, konstantin\} @primekey.se \\ ${ }^{3}$ Pro4u Open Source AB, Stockholm, Sweden \\ roger.kahlbom@pro4u.com \\ ${ }^{4}$ RedBridge AB, Kista, Sweden \\ \{stefan.andersson, jonas. feist\} @redbridge.se
}

\begin{abstract}
Many organisations are currently restricted in their choice of software because of restrictions imposed by existing systems. Challenges include a lack of interoperability and a risk of technological lock-in, which many small companies seek to address by utilising Open Standards and Open Source implementations of such standards when developing and deploying systems. This paper presents an overview of how the industrial research project ORIOS (Open Source software Reference Implementations of Open Standards) seeks to address identified challenges. An overarching goal of the project is to improve understanding within organisations of Open Standards, Open Source Reference Implementations, and the ecosystems around them. This will be done by developing a reference model of necessary and desirable features of an Open Standard, and how Open Standards and their implementations can be utilised by small companies in different usage contexts. An action case study approach will be used as a core strategy for evolving a reference model together with Swedish companies.
\end{abstract}

\section{$1 \quad$ Introduction}

Amongst many small companies it is widely recognised that Open Standards inherently open up markets by counteracting monopolies based on proprietary technologies. They also offer increased opportunities through promoting interoperability (Ghosh, 2005). Such approaches are being reinforced by a number of international initiatives, including the European Interoperability Framework (EIF version 1.0) which promotes Open Standards as part of a strategy for interoperability (EU, 2004). Previous research has shown the importance of using Open Standards for maintenance of digital assets in long-term usage scenarios (Lundell et al., 2011). 
The paper presents an overview of the ongoing ORIOS (Open Source software Reference Implementations of Open Standards) project, an industrial collaborative research project, which addresses a number of challenges experienced by small companies that relate to Open Standards and the potential for their implementation in Open Source software, including different types of lock-in and a lack of interoperability.

The central concepts and the scope for a reference model on Open Standards and their implementations in Open Source software which is to be developed during the project is presented in Figure 1. It clarifies that Open Standards can be implemented in Open Source Reference Implementations, and outlines that implementations of such standards can be used in different applications that are provided under different (proprietary and Open Source) software licenses.

The anticipated reference model characterises desirable properties for Open Standards and Open Source Reference Implementations for different usage scenarios and thereby provides guidance to different stakeholders groups and organisations in this domain. Somewhat simplified, an Open Standard is a standard which possesses certain 'openness' properties, and an Open Source Reference Implementation is a reference implementation of the specification of a standard that is licensed under an Open Source license. A Reference Implementation is an implementation of a specification which can be used as a definitive interpretation of the standard's specification.

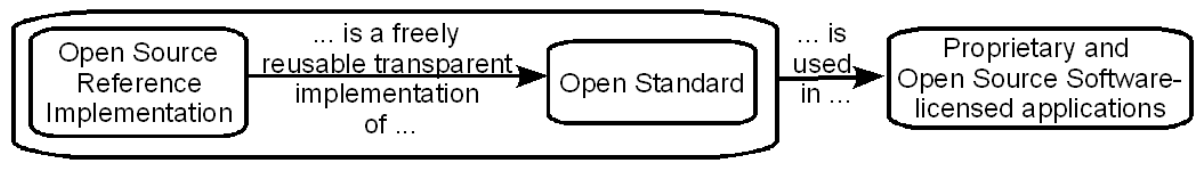

Fig. 1. Central concepts and the scope for a reference model to be developed

\section{$2 \quad$ Why Open Standards?}

According to the European Commissioner for Competition Policy: "Interoperability is a critical issue for the Commission, and usage of well-established open standards is a key factor to achieve and endorse it." (Kroes, 2008) A number of European countries are currently adopting national policies on Open Standards and some even require Open Standards in public procurement. For example, both the current and previous Swedish governments have expressed their support for Open Standards. With the directive ("Delegation för e-förvaltning", Dir. 2009:19) and SOU (2009:86) it is likely that Open Standards will play a much more significant role in the Swedish IT sector. The Swedish minister responsible for the e-Government Delegation has expressed strong support for Open Standards as defined in SOU (2009:86) and EIF version 1.0 (Odell, 2009).

Today, many companies and public sector organisations provide services to citizens and organisations that are dependent upon a well-functioning underlying 
IT-infrastructure. Much of this infrastructure is based on Open Standards, with the Internet and the web at its core. Many organisations, especially small companies, would simply not have existed without infrastructure and systems based on Open Standards. In essence, Open Standards drive innovation (Berners-Lee, 2010).

However, there is evidence of considerable confusion amongst software providers, software procurers and politicians about the meaning and impact of openness in standards (Lundell, 2011, 2012). This lack of clarity can have many negative impacts, from clouding the public debate over appropriate legislation to confusing potential customers about the importance of software compliance (Lundell, 2012). Therefore, whatever position is taken about Open Standards it seems clear that there is a pressing need for informed legislation on the one hand and informed decision making by purchasers and providers of software on the other. Anything less has the potential to reduce competitiveness in the hugely important global market in ICT.

\section{Challenges and Effects of Open Standards}

During the last decade, a number of European governments have adopted Open Standards in their policies in order to address a number of fundamental challenges in the ICT marketplace, such as lock-in, interoperability and procurement. There are a number of stakeholder roles in the marketplace that affect and are affected by the provision and adoption of Open Standards. The project addresses such challenges.

It is widely recognised that Open Standards, and especially when implemented in Open Source software, have the potential to address a number of fundamental challenges which are especially troublesome for small companies. First, a primary motivation for Open Standards is that they promote a healthy competitive market (Ghosh, 2005; Krechmer, 2005; Simcoe, 2006; Lundell and Lings, 2010). For example, the existence of an Open Standard reduces the risk and cost of market entry, and so encourages multiple suppliers. According to Simcoe (2006), this in turn leads to lower prices and improved product quality. A second motivation is that insistence on Open Standards reduces the risk to an organisation of being technologically locked-in. Open Standards increase control by supporting migration, thereby reducing an organisation's reliance on a single product or supplier (Ghosh, 2005; Krechmer, 2005; Berkman, 2005; Bhattacharya et al., 2007; Simon, 2005; West and Dedrik, 2001; Lundell, 2011). A third motivation is that Open Standards are a basis for interoperability. A significant current problem in many organisations is that they are restricted in their choice of software because of restrictions imposed by existing or legacy systems. Interoperability supports systems heterogeneity, thereby increasing options for organisations (Bird, 1998; Ghosh, 2005; Krechmer, 2005; Fomin et al., 2008). A fourth motivation is that Open Standards offer a basis for long-term access and reuse of digital assets, and in particular when supported by Open Source Reference Implementations (Behlendorf, 2009; Lundell et al., 2011). Having a precise definition of a digital format clearly offers some protection for the long-term interpretation of digitally stored materials; in extremis a converter could be written against the specification in the Open Standard. This is becoming an increasingly well recognised issue for many organisations, especially in the public sector (Gamalielsson 
and Lundell, 2010; Lundell, 2011; Lundell and Lings, 2010; National Archives Australia, 2006).

From these arguments, it is evident that different authors have expressed (and experienced) a variety of different desirable effects from the use of Open Standards, either in general or related to specific Open Standards. However, different views on and experiences related to these desirable effects have been expressed by different stakeholders in different roles related to an Open Standard. This is perhaps unsurprising given potentially different motives, goals and usage contexts for a specific Open Standard.

So, the question arises: what are the necessary and desirable features of an Open Standard, and how can Open Standards and their implementations be utilised by small companies in different usage contexts?

\section{The ORIOS Project}

The ORIOS project has two primary scientific objectives. The first is to explicate the concept of Open Standard and its implementation as Open Source Reference Implementations, thereby making it easier for stakeholders to communicate unambiguously about the costs, benefits and effects of different adoption options. This includes investigation of specific examples of Open Standards and Open Source Reference Implementations, and their effects on the market: in terms of penetration, support and overall impact. One important dimension of the study constitutes an investigation of impact within the Open Source area; particularly with respect to tools, implementations and platforms utilising the standards. The second is to develop a reference model, based on the investigations of specific examples of Open Standards and Open Source Reference Implementations, for guiding organisations on how to utilise Open Standards and Open Source Reference Implementations. The reference model provides detailed guidance, with concrete strategies, for how organisations can utilise Open Source Reference Implementations and Open Standards in different usage scenarios. The project focuses on Open Standards and Open Source Reference Implementations that are of particular interest to all partner companies.

The project undertakes an analysis of organisations and networks that are involved in realising the potential offered by adoption of Open Standards and Open Source Reference Implementations, as users and providers of software systems. In doing so, the study aims to galvanise existing knowledge of Open Standards, particularly in the context of Open Source Reference Implementations, and identify a critical path for Swedish organisations wishing to exploit these in a variety of business models. At root, the major issues around Open Standards and Open Source Reference Implementations exploitation are socio-technical and business oriented rather than purely technical.

To meet the objectives we will utilize an action case research approach (Braa and Vidgen, 1999). For the first objective this will be supplemented by a study of the appropriate literature reinforced with feed-in from interactive workshops, seminars, and a review of relevant projects (Open Standards, Open Source software, and Open Reference Implementation projects) in order to identify their different characteristics. 


\section{$5 \quad$ Discussion and Implications}

The project will provide a comprehensive understanding of the business models emerging from open strategies within specific usage contexts, and have immediate practical implications for business decision makers. Specifically, the project will establish an increased awareness in society and partner companies about opportunities and threats related to Open Standards and Open Source Reference Implementations. Such knowledge is especially important as it directly affects business conditions for small companies. For partner companies, the project will specifically raise awareness of interdependencies between Open Standards and the Open Source software ecosystems, and how this might impact on efforts to build a competitive software market.

It is expected that the project's overall approach will promote significant stakeholder and organisational learning, and improve Sweden's position for taking full advantage of the major international developments in Open Standards and Open Source Reference Implementations, their effect on Open Source software applications and the associated business opportunities which are likely to emerge with growing awareness and policy regulation.

Through our development of a reference model, we will establish key enablers and inhibitors for companies working in the Swedish context. The project will result in considerably increased exposure of Swedish organisations to the true potential of Open Standards and Open Source, which fundamentally affect all Swedish and international organisations.

\section{References}

Behlendorf, B.: How Open Source Can Still Save the World, Keynote Presentation, In 5th IFIP WG 2.13 International Conference on Open Source Systems, OSS 2009, Skövde, Sweden, 5 June (2009)

Berkman: Roadmap for Open ICT Ecosystems, Berkman Centre for Internet \& Society at Harvard Law School (2005)

Berners-Lee, T.: Long Live the Web: A Call for Continued Open Standards and Neutrality, Scientific American, 22 November, http://www.scientificamerican.com/ article.cfm?id= long-live-the-web\&print=true (2010)

Bhattacharya, J., Ilavarasan, P. V., Gupta, S.: Open standards and accessibility to information: a critical analysis of OOXML in India, In Proceedings of the 1st international Conference on theory and Practice of Electronic Governance, ICEGOV ‘07, vol. 232. ACM, New York, pp. 151-154 (2007)

Bird, G. B.: The Business Benefit of Standards, StandardsView 6(2), 76-80 (1998)

Braa, K., Vidgen, R.: Interpretation, intervention and reduction in the organizational laboratory: a framework for in-context information system research, Accounting, Management \& Information Technology 9, 25-47 (1999)

EU: European Interoperability Framework, European Commission, Version 1.0 (2004)

Fomin, V. V., Kühn Pedersen, M., de Vries, H. J.: Open Standards and Government Policy: Results of a Delphi Survey, Communication of the AIS 22(25), 459-484 (2008) 
Gamalielsson, J., Lundell, B.: Open Source Software for Data Curation of Digital Assets: a case study. In Proceedings of the 14th International Digital Media \& Business Conference: MindTrek 2010 (Lugmayr, A. et al., Eds.), ACM, New York, pp. 53-56 (2010)

Ghosh, R. A.: An Economic Basis for Open Standards, FLOSSPOLS, December, http: / / www. flosspols . org/deliverables / FLOSSPOLS-D04openstandards-v6.pdf (2005)

Krechmer, K.: The Meaning of Open Standards, In Proceedings of the 38th Hawaii International Conference on System Sciences - 2005, IEEE Computer Society, Los Alamitos, 10p (2005)

Kroes, N.: Being Open About Standards, Brussels, SPEECH/08/317, 10 June, European Commissioner for Competition Policy (2008)

Lundell, B.: e-Governance in public sector ICT-procurement: what is shaping practice in Sweden?, European Journal of ePractice 12(6), http://www.epractice.eu/en/ document/5290101 (2011)

Lundell, B.: Why do we need open standards?, In Proceedings of the 17th EURAS Annual Standardization Conference, European Academy of Standardisation, The EURAS Board, (to appear) (2012)

Lundell, B., Lings, B.: How open are local government documents in Sweden? A case for open standards. In Agerfalk, P. et al. (Eds.) Open Source Software: New Horizons, Springer, Berlin, pp. 177-187 (2010)

Lundell, B., Gamalielsson, J., Mattsson, A.: Exploring Tool Support for Long-term Maintenance of Digital Assets: a Case Study, In Fomin, V. \& Jakobs, K. (Eds.) Proceedings: 16th EURAS Annual Standardization Conference, European Academy of Standardisation, The EURAS Board, pp. 207-217 (2011)

National Archives Australia: Digital Preservation: illuminating the past, guiding the future, National Archives of Australia, Australian Government, June, http: / /www naa.gov . au/images/XENA_brochure\%5B15D_tcm16-47233.pdf (2006)

Odell, M.: Innovations for Europe: Increasing Public Value, Speech by Minister responsible for central government administration and local government issues, 5 Nov., Maastricht, http://www.regeringen.se/sb/d/11678/a/134858 (2009)

Simcoe, T. S.: Open Standards and intellectual property rights. In Chesbrough, H., Vanhaverbeke, W. and West, J. (Eds.) Open Innovation researching a new paradigm, Oxford University Press, Oxford (2006)

Simon, K.D.: The value of open standards and open-source software in government environments, IBM Systems Journal 44(2), 227-238 (2005)

West, J., Dedrick, J.: Proprietary vs. Open Standards in the Network Era: An Examination of the Linux Phenomenon, In Proceedings of the 34th Hawaii International Conference on System Sciences - 2001, IEEE Computer Society, Los Alamitos, 10p (2001) 